\title{
Two Cultures and Our Encyclopaedic Brain
}

\author{
JEA N - PIER R E CHANGEUX \\ Institut Pasteur \& Collège de France, Paris, France. Email: changeux@noos.fr
}

I support a fundamental principle stressed by the Encyclopédie, that the Unity of Knowledge is the direct consequence of the unity of the human brain. All of us are animated by what Claude Bernard called a 'kind of thirst for the unknown' which ennobles and enlivens scientific inquiry. We must humbly confess for now our immense ignorance - ignoramus. But to satisfy Claude Bernard's 'ardent desire for knowledge' we should never say, as some philosophers still do, ignorabimus about the human brain. Thanks to recent developments in neuroscience, we can now propose a common set of brain processes that account for the production of the diversity of knowledge. Thanks to these processes, we can work on a reunification of the true, the good and the beautiful, not as a uniform, monotonous culture, but as a network of cooperative diversity favouring intellectual and emotional exchanges among disciplines.

The title of C.P. Snow's book bluntly distinguishes 'two polar groups of persons: at one pole we have the literary intellectuals... at the other the scientists.' The book then develops the idea that 'the intellectual life of the whole of western society' is split into the titular two cultures - namely the sciences and the humanities. One cannot deny that in our current occidental societies - European or American - the cleavage still does exist. It already manifests itself at school. Sciences and humanities are taught by separate teachers and teachers in mathematics and literature receive themselves distinct trainings. Moreover, the academic and university system is subdivided into well-defined teaching disciplines regrouped within the basic sciences and the humanities.

The situation C.P. Snow comments upon is, to my opinion, institutionalized. It may be viewed as the product of a historical and sociocultural process mostly associated with the industrialization of the western societies and the extraordinary development of science and technology from the nineteenth century up to now. As a consequence of the growth, expansion and diversification of knowledge, it has become even more segmented in the age of the internet. 
I agree with Stephen Jay Gould's point of view that Snow's concept of 'two cultures' is 'not only off the mark but a damaging and short-sighted viewpoint that led to decades of unnecessary fence-building. ${ }^{, 1}$ I shall further argue that these 'disciplinary fences' are not inherent features of human culture; on the contrary. Some major Renaissance artists were also eminent mathematicians (Piero della Francesca) or engineers (Leonardo da Vinci). In the second part of the eighteenth century, the Encyclopédie responded to the demand of the intellectual community for a compilation of all human knowledge in reference to past and recent discoveries. It would be both secular and naturalistic and established by a mixed community of 'philosophes' including some of a literary bent, like Diderot, and others more scientifically oriented, like the mathematician d'Alembert. ${ }^{2}$

At the end of the Discours préliminaire, d'Alembert includes a chart entitled Figurative System of Human Knowledge with the aim to 'encompass the infinitely varied branches of human knowledge in a truly unified system' but 'not so rigid and strict as to impose limits on the search for new facts'. ${ }^{3}$ The Encyclopédie gathered all facets of knowledge into one unified text and through the endnotes to each article established links with other articles, thus for the first time creating a unique and open 'network of knowledge'. Interestingly for the neuroscientist, the chart of the Discours préliminaire distinguishes three fundamental constituents of human understanding which contribute to the diversity of all available knowledge. They are 'memory, reason and imagination', which represent the most eminent features of human brain functions ultimately unified by conscious processing. The tree of knowledge is thus rooted in the nature of the human brain. The unity of knowledge finds its origins in the unity of the human brain.

\section{The True, the Good and the Beautiful}

Plato conceived the intelligible world as structured into three transcendentals that he thought were present within a non-material and eternal world of forms: 'beauty, goodness and truth'. Aristotle already commented that these are not eternal forms but a set of universal 'categories' by which all things could be predicated. Immanuel Kant further wrote on the issue in his three great Critique books, of Pure Reason (1781) for truth, of Practical Reason (1786) for goodness, and of Judgment (1790) for beauty. ${ }^{4}$ Influenced by the physics of Newton, he already understood that there is a physical chain of interactions between things perceived and the one who perceives them with the faculty of the 'human mind to intuit objects'. Johann Sulzer in a supplement to Diderot's Encyclopédie in 1776 simply stated that the aesthetic, the moral, and the intellectual are distinct modes of understanding in humans. ${ }^{5}$

These three modes cut across the memory, reason, and imagination components mentioned in the Discours préliminaire. It means, to be clear, that one should distinguish, on the one hand, the general 'components' of knowledge acquisition of d'Alembert which apply to all forms of knowledge and confer them their unity and, on the other hand, the diversity of the 'modes' of existing knowledge including the true, 
the good and the beautiful. All of them are relevant features of the activity of the human brain, which should be analysed in a concomitant manner. ${ }^{6,7}$

E.O. Wilson in his book Consilience: The Unity of Knowledge proposed that " "jumping together" the linking of facts and fact-based theory across disciplines would create a common ground work of explanation': first by the unification of evolution with genetics, but also of the various forces of physics up to explaining consciousness and emotion in terms of brain activity. ${ }^{8}$ A neurobiology of aesthetics, as suggested for years now, and ultimately a science of artificial emotion become plausible. ${ }^{9,10}$ Yet, notably, neither Snow nor Wilson refer to 'goodness' or the ethical intention (in today's language). Is this for lack of interest? Or, deliberately, as a consequence of a puritanical establishment setting apart the non-material status of the 'goodness transcendental'?

\section{The Brain as Generator of Knowledge}

The thesis I wish to defend is in the tradition of the pre-Socratic philosophers, of Spinoza and Diderot, and of secular humanism that natural laws explain the workings of the universe and in particular that of the brain. As already stated by Helmholtz, Brücke and the Berlin group in their famous 1847 Manifesto, the aim of scientific research in the life sciences is to show 'that there are no alternative forces other than the current physico-chemical ones in action in the organism' in particular in the brain. This was no simplistic and naïve reductionist statement: it was a courageous stance then, and it still is. It asks what an adequate scientific model of the human brain is, and how one tests it, bottom-up from molecules to consciousness and top-down from human behaviour to brain chemistry.

The idea that there exists a common set of brain processes that account for the production of the diversity of knowledge modes becomes plausible in light of recent developments in neuroscience. They offer opportunities - admittedly still fragmentary - to establish concrete 'bridges' between what is often referred to as the 'mental' and the 'neuronal'. First, a common idea is that the brain is the hardware of the machine above which would stand the 'mind' as an autonomous 'program' with its semantic and syntactic levels. This scheme, while it may look computationally correct, is simply inadequate from a biological point of view. Since Claude Bernard, in the life sciences, knowledge progresses through the establishment of a causal and reciprocal relationship between structure and function. The nervous system is not a single-level machine like classical computers but shows a high level of complexity resulting from several 'interlocked levels of functional organization' - including distinct levels of cognitive function. ${ }^{9-12}$ These hierarchically organized levels and the dependencies between them are established through bottom-up and top-down feedback connections, or re-entrant mechanisms. ${ }^{6,11-13}$ Any particular brain function physiological and ultimately behavioural - is causally related to such defined connectional architecture(s).

Let's take the case of visual perception as an illustrative example. The vertebrate eye is a remarkable optical instrument in which a lens focuses a visual image on the 
retina. The sensitive layer of the retina is formed of rod and cone receptor cells which contain pigment molecules responding, in the rods, to relatively low intensities of light, but without colour information, whereas in the cones they are colour-sensitive. The contemplation of a painting as well as its creation ultimately rely upon the collective conformational transition of these photoreceptive pigment molecules and the subsequent production of an electrical response. The relevant retinal map of electrical responses then propagates from the retina to the visual cortex, maintaining an accurate topography. This image is then relayed from map to map in the various functional levels of the cortex, from primary to secondary and higher visual cortical areas as far as the prefrontal lobe. There is thus an ascending isomorphism of the representation of the outside world, which is accompanied by what one might call a descending top-down 'ego-morphism'. Starting with David Hubel and Torsten Wiesel in the 1950s a fair description of visual perception has been achieved, thus justifying the term of 'mental objects' for the bio-physical implementation of knowledge in the brain. 6,7

Our brain is the generator of all knowledge present on this planet. To account for the incessant genesis of new representations (d'Alembert's 'imagination') the hypothesis was proposed that the brain is in constant evolution and the seat of some kind of Darwinian 'epigenetic generator" ${ }^{14-16}$ that would be governed by a generalized variation-selection mechanism which does not directly involve changes at the genome level. ${ }^{6,13-16}$ As stated by H. Simon,

The task of the generator is to produce variety, new forms that have not existed previously, whereas the task of the test is to cut out the newly generated forms so that only those that are well fitted to the environment will survive. ${ }^{12}$

Within the brain, these forms are the mental objects just described in the case of visual perception. I have held that the spontaneous electrical activity (which shows both organization and variability), recently named 'default network' by Raichle, ${ }^{16}$ is a source of an 'epigenetic' diversity that occurs in the brain prior to an interaction with the outside world. ${ }^{6,17}$ Such 'wandering' spontaneous activity would take the form of transient patterns of active neurons, 'neuronal assemblies' or 'pre-representations' linked through collective changes of synaptic efficicacies. ${ }^{6,18}$ These include anticipations, schemas, imaginations, and so on. At one end, they may be viewed as neural implementations of the 'vicarious trial and error' behaviour identified in animal species such as rats or mice, ${ }^{19}$ at the other end they would correspond to Gilles Fauconnier's generative process of 'blending' in linguistics, ${ }^{20}$ associating representations that are far apart from each other. Among such rich diversity, selection of pre-representations would take place through the intervention of a reward, ${ }^{21}$ and/or an anticipation of reward, ${ }^{22}$ evoked by the interaction of the organism with the outside environment and/or with the 'inner world' of the subject. Neurotransmitters such as dopamine and acetylcholine are known to play a role in mediating these responses. The selection process would then establish a relationship between the inner representation of the brain and the outside world. The natural world is unlabelled and the 
human brain constantly attempts to label it, thus creating the constantly growing network of knowledge.

These selected representations of the world are stored in brain's long-term memory, which for d'Alembert is an important 'component' in knowledge acquisition and amplification.

A major additional feature of the human brain is that these components might be stored in external memories - in brain prostheses - such as writings, works of art, etc., made up of materials, clay, stone, paper, paintings, or electronic supports, and so on, which are more stable than the brain memories and which can be steadily exploited by the brain.

\section{The Diversification of Knowledge}

An important issue then becomes how it happens that the common brain selection mechanism just described produces the immense set of representations covered by the three main 'modes' of human understanding: the scientific, the aesthetic and the moral. Johann Nikolaus Tetens ${ }^{23}$ already argued that this triadic scheme corresponds to 'three main vital powers: that of cognition, that of desire, and that of the feeling of pleasure and displeasure', and also mentioned the obvious need for a continuous process of secular negotiation in their constantly evolving production. From a neurocognitive perspective, the diversity and variability of these 'modes of understanding' is made possible because of the gigantic parallel organization of the human brain and its multiple processing devices. These modes would represent the basic modes of exploration and processing of the world which are 'rewarding' for the subject. They might be rewarding in their relationships with him/herself and with other individuals within the social group and would then correspond to the principal modes of social communication: through rational thinking (science), rules of conduct (ethics) and shared emotional feelings (art) and their frequent overlap. In all of them, language is the privileged vehicle for social communication, although, in aesthetics, alternative media (painting, music, dance, movie, theatre) appear more pregnant. Their diversity would arise from the multiple exchanges and reward opportunities available in the actual physical and social environment of the individual.

Another aspect of the diversification of the mental objects is that even if they result from the activity of multiple parallel non-conscious processors, they end up as a common, global, subjective experience. In other words, they are consciously processed before being externally produced and communicated. The long-distance axons between brain neurons would then broadcast the information to many other processors, brain-wide and with defined spatial distribution, ultimately leading to a report of conscious experience and its communication to the social group. ${ }^{24-29}$ In its original formulation, this Global Neuronal Workspace (GNW) model included reward mechanisms as a critical component for the conscious selection of the behavioural response.

In the case of aesthetic experience, ${ }^{9,10,30,31}$ contemplation of a work of art could then be hypothesized to selectively mobilize a discrete and singular synthesis - within 
the personal conscious GNW - of external perceptions of 'forms, figures and fables' (Chastel) together with defined distributions of colour patterns/sound harmonies, inner memories of stored emotions, former experiences of works of art. Some kind of unanticipated 'singular ignition' or global catharsis (Vygotsky) would recruit brain territories ranging from the primary and secondary visual areas, the limbic system, the prefrontal cortex, etc.

In the case of rational thinking, for instance a prefrontal auto-evaluation loop would help to consciously articulate - in a deliberate and critical manner - a sequence of representations aiming at the agreement of knowledge with itself, which ultimately results in a sound conclusion. In the case of ethics, rules of conduct would be forged with the aim of 'a good life with and for others', for instance through the mobilization of empathy and sympathy circuits via a prefrontal/limbic loop. ${ }^{32,33}$ But overlap and cooperation between these systems may take place.

\section{Synaptic Epigenesis and the Origin of Culture}

Last, an important and unique feature of human brain evolution is the extension of its postnatal development for up to 15 years and, as a consequence, the production of a culture that includes several aspects of human behaviour, including language, social practices (kinship and marriage), systems of beliefs, technologies, institutions for a particular social group, etc., which may be stored in internal but also 'external memories'. It is causally related with its outburst - or 'explosive' - development in human societies. Culture is in constant evolution and perpetuated by social relearning from generation to generation.

An approximately fivefold increase in brain weight accompanies postnatal development, during which about half of all adult synaptic connections are formed at a very fast pace (millions of synapses per second). ${ }^{34}$ This multistep process contributes to the formation and shaping of the synaptic architecture of the adult human brain in direct relation with the physical and social environment of the developing child. The postnatal synaptogenesis process reveals a cascade of multiple nested steps where epigenetic processes of variation-selection take place. ${ }^{35-39}$ This transient diversity is then reduced by selective stabilization of some of the labile contacts and elimination (or retraction and/or pruning) of others. The evoked activity together with the spontaneous activity of the developing brain is able to regulate the storage in its connectivity of 'imprints' of its physical and social environment. As a consequence, an important phenotypic variance of brain connective organization accompanies the epigenetic selection process. ${ }^{13,14,36}$

Among the many manifestations of cultural evolution, writing and reading appear as recent inventions (approximately 8000 years ago) that exert considerable demands on our cognitive system but also 'open' brain access to libraries of stored writings and now to global information networks. The first evidence for specialized brain circuits for writing and reading was the discovery by Dejerine in the 1900s of 'pure alexia', ${ }^{4}$ which causes severe reading problems as a consequence of specific bundles of myelinated axon lesions, while other language-related skills remain intact. Acquisition of 
reading and writing may be viewed as an example of epigenetically laid down 'cultural circuits' following epigenetic 'appropriation' of fast-developing connections at around 5 years of age. ${ }^{6,36,39}$ Written language learning is but one of many social and cultural imprints 'competitively' acquired during the development of the human brain including the use of the internet in the 'age of Twitter'. As a major consequence, the acquisition of skills and practices associated with the symbolic experience and emotional labelling characteristic of rational thinking (science), rules of conduct (ethics), and shared feelings (art) become stably internalized in the connectivity of the brain and become exclusive of others. Their 'forgetting' is considerably slower than their speed of acquisition. They contribute to what Bourdieu refers to as the 'habitus' of the subject: internalized routine modes of perception, action, and evaluation, which often last a lifetime.

Possibly, since the domestication of fire, the grouping of human individuals into stable, autonomous and geographically dispersed societies has led to the differentiation and divergence of cultures between human groups with separate languages, knowledge backgrounds, techniques and, most of all, systems of beliefs, thus raising cultural fences. These fences, as already noted by Claude Levi Strauss in Race et Histoire, ${ }^{41}$ are such that, because of its different culture, 'the other' may no longer be regarded as a human being. A 'dehumanization' process frequently accompanies the diversification of cultures. ${ }^{42}$ Most often, a widespread 'ethnocentrism' of the subject takes place, where he/she considers his/her own culture as 'The only One Culture' existing on earth. Such cultural habitus acquired in the child and 'printed' in its brain remains stable for years or even decades. It manifests itself, for instance, in the accent in spoken language. It can only be fully renewed with the re-learning step that takes place with the next generation.

\section{Re-unifying The True, the Good and the Beautiful and the Future of Humanity}

C.P. Snow's 'Two Cultures' cleavage is typical of an anecdotal cultural confrontation arising in our western societies from the pitfalls of an elitist occidental educational system. This is minor compared with the abyssal cultural confrontations that we face nowadays throughout the world. To justify cultural differences, language, holy books, ethical rules, food or clothing rituals are evoked as irreducible transcendentals even more fundamental than political/economical differences. The universe of cultural differences and thus of potential conflicts is immense, even if from the knowledge point of view, it bears upon a limited number of 'external' features. How to face this dramatic situation. How to overcome the cultural fences that plague our planet?

One possibility to consider is to make an effort to gain some distance with respect to the emotions mobilized by what is believed to be a 'transcendental' act of faith. This might be achieved, at the individual level, through the understanding that such belief is simply an acquired cultural trait invented and epigenetically perpetuated by human societies to consolidate their social bond. Following Durkheim, such social facts would possess an objective reality that could be 'studied like a physicist studies 
the physical world,' taking into account the fact that they are produced and propagated in a steadily evolving socio-historic context. ${ }^{43}$ The relevant scientific and critical analysis may help in the needed distancing from systems of beliefs needed to lower cultural fences and most of all offer new possibilities for subjects to evolve in their opinions, 'Penser d'après soi' and 'penser par soi-même' are famous statements of D'Alembert.

Another possibility advocated by Levi-Strauss is to look for a 'coalition of cultures'. According to Levi-Strauss 'no culture is alone; it is always in coalition with other cultures, which let it build up cumulative series'. ${ }^{41}$ Such a coalition would contribute to some kind of cultural 'generator of diversity', favouring the evolution of cultures. An example is the Renaissance encounter of Greek, Roman, Arab and even Chinese cultures with European culture. Another is the famous case of Picasso's 'Demoiselles d'Avignon', the first cubist painting to meld African art with European realism. Levi-Strauss's statement that 'All cultural progress is the function of a coalition between cultures' means that the occurrence of a coalition favouring progress and cooperation rather than exclusion requires the breakdown of the cultural fences.

A further interesting prospect is to reframe the system of values currently used in our present occidental societies in their political choices. Our mode of living rests upon an economic liberalism based upon a market economy and private property favouring free trade and competition - or 'laissez-faire' - to determine the price, production and consumption of goods. The means of production are operated for profit. If economic liberalism ignores cultural barriers it also largely ignores ethical issues and, in particular, the ultimate repartition of goods on the planet and the welfare of the latter's citizens. This results in dramatic inequalities that ultimately lead to the building up of cultural barriers if not of physical walls (see the Middle East, US-Mexico). Values alternative to profit are not central in such a system. An interesting question is to what extent the 'good' may rejoin the 'beautiful' favouring a society radically different from the current one, which would dissolve cultural barriers to the benefit of an unanticipated aesthetic quality of life. ${ }^{44}$

A last possibility - seemingly easier to achieve - is to be found in education. As stated by John Dewey, 'education is a regulation of the process of coming to share in the social consciousness; and that the adjustment of individual activity on the basis of this social consciousness is the only sure method of social reconstruction. ${ }^{45}$ Cultural differences are infused into the child brain already at birth (possibly even before for language), in the family environment, and consolidated by the schooling system. Because of the exceptional plasticity of the child's brain, traditional families and 'communautarianist' groups often insist on their willingness to confine their young children (without their informed consent) in confessional schools. Secular education (école laïque) has the exactly opposite objective. ${ }^{33}$ It is a system of public education, in countries with a secular government separating religion and state - like the French public educational system - where conspicuous religious symbols as well as the biased unilateral presentation of the diversity of symbolic systems have been banned. Still it has been recognized as one of the best systems in the world to learn and practice tolerance and respect for cultural differences. 
In conclusion, starting form the Two Cultures cleavage of C.P. Snow and continuing with a discussion of widespread cultural differences, including systems of beliefs, my aim has been to challenge the barriers of communication between fields and disciplines caused by cultural differences as opposing the progress of knowledge (by fighting obscurantism) and the establishment of peaceful relationships between human beings. To do so, I tried to defend an even more fundamental principle stressed by the Encyclopédie: that of the Unity of knowledge as a straightforward consequence of the unity of the human brain. All of us are animated by what Claude Bernard called a 'kind of thirst for the unknown' that ennobles and enlivens scientific inquiry. We must humbly confess for now our immense ignorance-ignoramus. But to satisfy Claude Bernard's 'ardent desire for knowledge' we should never say, as some mysterianist philosophers still do, ignorabimus, especially about the human brain. All of us should then work toward a re-unification of the true, the good and the beautiful, thanks to our brain; but we should not do so as a uniform monotonous culture but as a system of cooperative diversity favouring exchanges between disciplines. This approach looks more than ever necessary for our brain to invent new forms of social life, making possible the survival of a dramatically endangered humanity and hopefully a global improvement in its quality of life.

\section{Acknowledgements}

The author thanks Dr Henri Korn for helpful suggestions and comments. This project has received funding from the European Union's Horizon 2020 Research and Innovation Programme under Grant Agreement No. 720270 (HBP SGA1).

\section{References}

1. S.J. Gould (2003) The Hedgehog, the Fox, and the Magister's Pox (New York: Harmony Books).

2. G. Weissmann (2007) Encyclopedias of life: from Diderot to the Yeti crab. The FASEB Journal, 21, 2267-2271.

3. J. le Rond D'Alembert (1751) Discours préliminaire de l'Encyclopédie. In Encyclopédie ou Dictionnaire raisonné des sciences, des arts et des métiers.

4. I. Kant (1781) Critique of Pure Reason (Kritik der reinen Vernunft) for truth, (1788) Critique of Practical Reason (Kritik der praktischen Vernunft) for goodness and (1790) Critique of Judgement (Kritik der Urteilskraft) for beauty.

5. J.G. Sulzer (1771-1774) Encyclopedia of Fine Arts a supplement to Diderot's Encyclopédie.

6. J.-P. Changeux (1983) L'Homme neuronal (Paris: Fayard); J.-P. Changeux (1985) Neuronal Man (Laurence Garey translator) (New York: Pantheon Books).

7. J.-P. Changeux (2008) Du vrai, du Beau, du Bien, un nouvelle approche neuronale (Paris: Odile Jacob); J.-P. Changeux (2012) The Good, the True, the Beautiful. A Neuronal Approach (Laurence Garey translator) (New Haven: Yale/Odile Jacob).

8. E.O. Wilson (1998) Consilience: The Unity of Knowledge (New York: Knopf). 
9. J.-P. Changeux (1994) Creative process: art and neuroscience. Leonardo, 27, pp. 189-201 (special issue 'Art and Science: Similarities, Differences and Interactions').

10. J.-P. Changeux (2012) Beauty in the brain: for a neuroscience of art. Rendiconti Lincei, 23, 315-320.

11. J.-P. Changeux (2017) Climbing brain levels of organisation from genes to consciousness. Trends in Cognitive Science, 21, pp. 168-18.

12. H. Simon (1962) The architecture of complexity. Proceedings of the American Philosophical Society, 106(6), pp. 467-482; H. Simon (1969) The Sciences of the Artificial (Cambridge, MA: MIT Press), p. 52.

13. G. Edelman (1987) Neural Darwinism. Selection Neural Groups Theory (New York: Wiley).

14. J.-P. Changeux, P. Courrege and A. Danchin (1973) A theory of the epigenesis of neuronal networks by selective stabilization of synapses. Proceedings of the National Academy of Sciences of the USA, 70, pp. 2974-2978.

15. J.-P. Changeux, J.P. and A. Danchin (1976) Selective stabilisation of developing synapses as a mechanism for the specification of neuronal networks. Nature, 264, pp. 705-712.

16. M.E. Raichle, A.M. MacLeod, A.Z. Snyder, W.J. Powers, D.A. Gusnard and G. L. Shulman (2001) A default mode of brain function. Proceedings of the National Academy of Sciences of the USA, 98, pp. 676-682; see also M. Raichle (2010) The brain's dark energy. Scientific American, 302(3), p. 4.

17. S. Dehaene and J.-P. Changeux (2005) Ongoing spontaneous activity controls access to consciousness: a neuronal model for inattentional blindness. PLoS Biology, 3(5), e141.

18. R.E. Beaty, M. Benedek, P.J. Silvia and D.L. Schacter (2016) Creative cognition and brain network dynamics. Trends in Cognitive Science, 20, pp. 87-95.

19. A.D. Reddish (2016) Vicarious trial and error. National Review of Neurosciences, 17, pp. $147-159$.

20. G. Fauconnier and M. Turner (2002) The Way We Think: Conceptual Blending and the Mind's Hidden Complexities (New York: Basic Books).

21. S. Dehaene and J.P. Changeux (1991) The Wisconsin card soring test: theoretical analysis and modeling in a neuronal network. Cerebral Cortex, 1, pp. 62-79.

22. M.A. Bermudez and W. Schultz (2014) Timing in reward and decision processes. Philosophical Transaction of the Royal Society London B, Biological Science, 369, p. 20120468.

23. J.N. Tetens (1777) Philosophische Versuche über die menschliche Natur und ihre Entwickelung, Vol. 1 and Vol. 2.

24. J.P. Changeux and S. Dehaene (2008) The neuronal workspace model: conscious processing and learning. In: R. Menzel, (Ed.) Learning Theory and Behavior, Vol. [1] of Learning and Memory: A Comprehensive Reference, 4 vols J. Byrne, Editor (Oxford: Elsevier), pp. 729-758.

25. B. Baars (1998) A Cognitive Theory of Consciousness (Cambridge: Cambridge University Press).

26. S. Dehaene, M. Kerszberg and J.-P. Changeux (1998) A neuronal model of a global workspace in effortful cognitive tasks. Proceedings of the National Academy of Sciences: USA, 95, pp. 14529-14534.

27. S. Dehaene and J.P. Changeux (2005) Ongoing spontaneous activity controls access to consciousness: a neuronal model for inattentional blindness. PLoS Biology, 3(5), e141. 
28. H.C. Lou, J.-P. Changeux and A. Rosenstand (2016) Towards a cognitive neuroscience of self-awareness. Neuroscience and Biobehavorial Reviews, 11 April, S0149-7634(16)30041-0.

29. J.-P. Changeux and H.C. Lou (2011) Emergent pharmacology of conscious experience: new perspectives in substance addiction. FASEB Journal, 25, 2098-2108.

30. C.J. Cela-Conde, G. Marty, F. Maestú, T. Ortiz, E. Munar, A. Fernández, M. Roca, J. Rosselló and F. Quesney (2004) Activation of the prefrontal cortex in the human visual aesthetic perception. Proceedings of the National Academy of Sciences, 101, pp. 6321-6325.

31. H. Kawabata and S. Zeki (2004) Neural correlates of beauty. Journal of Neurophysiology, 911, pp. 1699-1705.

32. J.-P. Changeux and P. Ricoeur (1998) Ce qui nous fait penser: La Nature et la Règle (Paris: Odile Jacob); J.-P. Changeux and P. Ricoeur (2000) What Makes us Think? A Neuroscientist and a Philosopher Argue about Ethics, Human Nature and the Brain (M.B. De Bevoise, translator) (Princeton: Princeton University Press).

33. K. Evers and J.-P. Changeux (2016) Proactive epigenesis and ethical innovation: A neuronal hypothesis for the genesis of ethical rules. EMBO Reports, 17, pp. 1361-1364.

34. H. Lagercrantz, M.A. Hanson, L.R. Ment and D.M. Peebles (2010) The Newborn Brain (2nd edn) (Cambridge, UK: Cambridge University Press).

35. J.-P. Bourgeois (1997) Synaptogenesis, heterochrony and epigenesis in the mammalian neocortex. Acta Paediatrica Supplement, 422, 27-33.

36. J.-P. Changeux (2012) Synaptic epigenesis and the evolution of higher brain functions. In: P. Sassone-Corsi and Y. Christen (Eds), Epigenetics, Brain and Behavior, 11, Research and Perspectives in Neurosciences (Berlin, Heidelberg: Springer-Verlag), pp. 11-22.

37. T.N. Wiesel and D.H. Hubel (1963) Effects of visual deprivation on morphology and physiology of cells in the cat's lateral geniculate body. Journal of Neurophysiology, 26, pp. 978-993.

38. P. Benoit and J.-P. Changeux (1978) Consequences of blocking the nerve with a local anaesthetic on the evolution of multiinnervation at the regenerating neuromuscular junction of the rat. Brain Research, 149, 89-96.

39. D. Purves and J.W. Lichtman (1980) Elimination of synapses in the developing nervous system. Science, 210, pp. 153-157.

40. J. Dejerine (1901) Anatomie des centres nerveux (with Augusta Marie DejerineKlumpke), 2 vols (Paris: Rueff).

41. C. Levi Strauss (1952) Race et Histoire (Paris: UNESCO).

42. I. Fried (1997) Syndrome E. Lancet, 350, pp. 1845-1847.

43. E. Durkheim (1912) Les Formes élémentaires de la vie religieuse: le système totémique en Australie (Paris: Félix Alcan).

44. J.E. O'Brien (2016) Critique of Rationality: Judgement and Creativity from Walter Benjamin to Maurice Merleau-Ponty (Leiden and Boston: Brill).

45. J. Dewey (1897) My pedagogic creed. School Journal, 54 (Jan. 1897), pp. 77-80. 


\section{About the Author}

Jean-Pierre Changeux is Professor Emeritus at the Collège de France Department of Neurosciences, Pasteur Institute, Paris. At the advent of the era of molecular biology, Jean-Pierre Changeux pioneered the study of the role of conformational changes linking topographically distinct sites in regulatory processes. His $\mathrm{PhD}$ studies, carried out under the supervision of Jacques Monod, provided the experimental basis for the formal model of allosteric regulatory interactions in bacterial regulatory enzymes, which was put forward in a paper that has become one of the hundred most quoted papers of world scientific literature. Throughout a long career, Changeux has consistently built upon and extended his early theory, to spawn many new and flourishing fields of investigation

His main contributions and discoveries in the course of the past 40 years are centred on the general theme of receptor mechanisms, primarily in the nervous system, and were initiated by the first identification of a neurotransmitter receptor: the nicotinic acetylcholine receptor. He combined approaches from supposedly disparate disciplines of pharmacology, molecular biology and developmental biology as well as behavioural and pathological studies, as and when required. His contributions to understanding the regulation of acetylcholine receptors in turn contributed to advancing our understanding of the nature of long-term synaptic plasticity within neural networks. His seminal work on the nicotinic receptor and its allosteric modulation has pioneered new fields of research in signal transduction mechanisms, molecular pharmacology and pathology of chemical communications in the nervous system.

The publication of his book Neuronal Man: The Biology of The Mind in 1985 brought Changeux celebrity status among the wider public. Since then he authored or co-authored several other books directed towards the non-scientific public, notably Conversations on Mind Matter and Mathematics with the mathematician Alain Connes (1998), What Makes Us Think with the philosopher Paul Ricoeur (2002) and the Physiology of Truth (2002), which initiated an instructive dialogue between the two often-hostile disciplines of neuroscience and philosophy. He is also concerned with the relationships between aesthetic experience and the brain (Raison \& Plaisir, 1994) and has recently published Du Vrai, du Beau, du Bien (2009) that summarizes 30 years of teaching at the Collège de France.

Jean-Pierre Changeux's many academic accolades include the Gairdner Foundation Award in 1978, the Wolf prize in 1983, the Louis Jeantet Prize for Medicine in 1993, the Goodman and Gilman Award in drug receptor pharmacology in 1994, the Balzan Prize in 2001, the Lewis Thomas Prize for Writing about Science in 2004, the Olav Thoan prize in 2016 and the Albert Einstein World Award of Science in 2018. $\mathrm{He}$ is foreign associate of the National Academy of Sciences USA, among several academies. 